Journal of Zhejiang University-SCIENCE B (Biomedicine \& Biotechnology) ISSN 1673-1581 (Print); ISSN 1862-1783 (Online)

www.jzus.zju.edu.cn; www.springerlink.com

E-mail: jzus@zju.edu.cn

Retraction Note:

\title{
Retraction Note to: Ambient air pollution and adverse birth outcomes: a systematic review and meta-analysis
}

\author{
Le-qian $\mathrm{GUO}^{1}$, Yu $\mathrm{CHEN}^{2}$, Bai-bing MI ${ }^{1}$, Shao-nong $\mathrm{DANG}^{1}$, Dou-dou ZHAO ${ }^{1}$, \\ Rong LIU $^{1}$, Hong-li WANG ${ }^{1}$, Hong YAN $\$ 1$ \\ ${ }^{1}$ Department of Epidemiology and Biostatistics, School of Public Health, Xi'an Jiaotong University Health Science Center, Xi'an 710061 , China \\ ${ }^{2}$ Medical Records Department, the First Hospital of Yulin, Yulin 718000, China \\ †E-mail: yanhong1234@aliyun.com
}

https://doi.org/10.1631/jzus.B18r0122

Retraction Note to: J Zhejiang Univ-Sci B (Biomed \& Biotechnol) 2019 20(3):238-252 https://doi.org/10.1631/jzus.B1800122

The authors have retracted this article (Guo et al., 2019) because some data from the original literature had not been converted to appropriate units in the paper, which resulted in deviation of the meta-analysis results. For example, for the forest plot used to examine associations between $\mathrm{PM}_{10}$ exposure and the risk of adverse birth outcomes, the estimates from Brauer et al. (2008), Pedersen et al. (2013), Zhao et al. (2015), and Hansen et al. (2006) were on the originally reported scales of $1 \mu \mathrm{g} / \mathrm{m}^{3}, 10 \mu \mathrm{g} / \mathrm{m}^{3}, 10 \mu \mathrm{g} / \mathrm{m}^{3}$, and Inter Quartile Range, respectively. None of these estimates had been converted to $20 \mu \mathrm{g} / \mathrm{m}^{3}$ increase scale that was stated in the article. Similar problem exists in the analysis on associations between $\mathrm{NO}_{2}$ exposure and risk of adverse birth outcomes. Therefore, the results of the meta-analysis are misleading.

All authors have agreed to this retraction and express their deepest apologies to the original authors, publishers, and readers.

\section{References}

Brauer M, Lencar C, Tamburic L, et al., 2008. A cohort study of traffic-related air pollution impacts on birth outcomes. Environ Health Perspect, 116(5):680-686. https://doi.org/10.1289/ehp.10952

Guo LQ, Chen Y, Mi BB, et al., 2019. Ambient air pollution and adverse birth outcomes: a systematic review and metaanalysis. J Zhejiang Univ-Sci B (Biomed \& Biotechnol), 20(3):238-252. https://doi.org/10.1631/jzus.B1800122

Hansen C, Neller A, Williams G, et al., 2006. Maternal exposure to low levels of ambient air pollution and preterm birth in Brisbane, Australia. BJOG, 113(8):935-941. https://doi.org/10.1111/j.1471-0528.2006.01010.x

Pedersen M, Giorgis-Allemand L, Bernard C, et al., 2013. Ambient air pollution and low birthweight: a European cohort study (ESCAPE). Lancet Respir Med, 1(9):695-704. https://doi.org/10.1016/s2213-2600(13)70192-9

Zhao N, Qiu J, Zhang YQ, et al., 2015. Ambient air pollutant $\mathrm{PM}_{10}$ and risk of preterm birth in Lanzhou, China. Environ Int, 76:71-77.

https://doi.org/10.1016/j.envint.2014.12.009

\footnotetext{
The online version of the original article can be found at https://doi.org/10.1631/jzus.B1800122

ॠ Corresponding author

(C) Zhejiang University and Springer-Verlag GmbH Germany, part of Springer Nature 2020
} 